\title{
Effect of Pore Radius Distribution of Forest Soils on Vertical Water Movement in Soil Profile
}

\author{
森林土壌の孔隙径分布特性が土層内の鉛直水分移動に及ほす影響の解析 \\ Ken'ichirou KOSUGI* Gradvate School of Agriculture, Kyoto University \\ 小杉蜸一朗 \\ (京都大学大学院農学研究科)
}

\begin{abstract}
In order to clarify the effect of soil pore radius distribution $g(r)$ on the water movement in soil profile, one-dimensional vertical flow equation was solved by using the model for soil hydraulic properties which was derived by applying lognormal distribution laws to $g(r)$. Results showed that the recession hydrograph from a soil profile becomes gradual as the median of $g(r)$ increases. For soil with a relatively large median of $g(r)$, the recession hydrograph becomes steep as the width of $g(r)$ increases. When the median of $g(r)$ is relatively small, the hydrograph has more gradual decreases in recession flow as the width of $g(r)$ increases. This critical median value increases as the length of soil profile $(L)$ becomes small. By comparing pore radius distributions of various soils, it was shown that the undisturbed forest soils yield greater amount of recession flow than the disturbed loamy soils. 70 percent of the disturbed sandy soils yield greater amount of recession flow than the forest soils with $L$ of $100 \mathrm{~cm}$. When $L$ is $50 \mathrm{~cm}$, hydrographs of half of the sandy soils have greater decreases in recession flow than those of the forest soils. Hydrographs from the crumb-structure forest soils have more gradual decreases in recession flow than those from the granular-structure forest soils. Recession hydrographs from the massive forest soils are steeper than the those from the crumb and granular-structure soils. As a result, it was indicated that well-developed forest soil is effective as the surface soil to increase baseflow from hillslope.
\end{abstract}

Key words: Soil water movement, Pore radius distribution, Soil hydraulic properties, Forest soil, Lognormal distribution

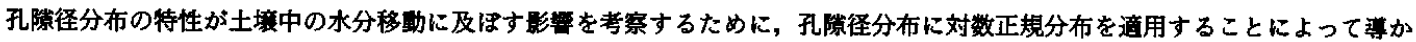
れた土壤水分特性のモデルを用いて鉛直一次元漫透の基楚式の解析を行った。その結果, 孔陵径分布のメジアンが大きいほど土層か

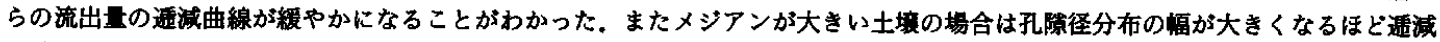
曲線が急になり，逆にメジアンが小さい土筡では分布の幅が大きくなるほど违減曲線が緩やかになることが示された。このメジアン

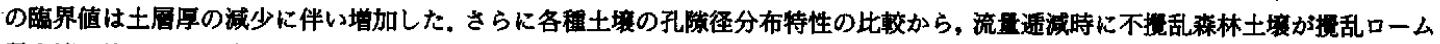

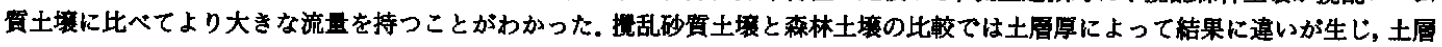

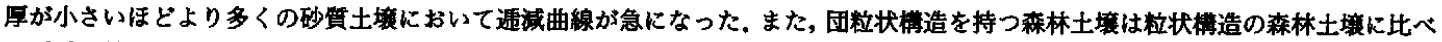

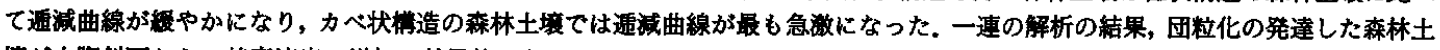
壤が山腹斜面からの基底流出の増加に効果的であることが示唆された。

キーワード：土境水分移動, 孔陵径分布, 土境水分特性, 森林土境, 対数正規分布

\section{I . INTRODUCTION}

Modeling the storm runoff process in forested watersheds is important for the management of water resources, as well as for predicting slope failure caused by heavy rainfall. Because forested hillslopes are usually covered with forest soils which have peculiar pore radius distribution and hydraulic properties, it is important to evaluate the effect of forest soils

\footnotetext{
*京都大学大学院票学研究科 $=606-01$ 京都市左京区北白川追分町

Graduate School of Agriculture, Kyoto University, Kyoto 606-01, Japan
} 
on the water movement in forested watersheds. It has been frequently pointed out that the existence of large size pores increases the permeability of forest soil. This reduces the surface flow on forested hillslope and increases the amount of water which infiltrates into the soil profile (e.g., Tsukamoto, 1992).

In recent years, many hydrologists have studied the effect of hydraulic properties of forest soils on the movement of water infiltrated into the soil profile by using the models for soil water retention and hydraulic conductivity. Kubota et al . (1987) combined the water retention model proposed by Klute and Heermann (1974) with the relative hydraulic conductivity model proposed by Leibenzon (1947) for analyzing the downslope flow on forested hillslopes. Ohte (1992) analyzed vertical water flow in a forest soil using the combined water-retentionhydraulic-conductivity model developed by Brooks and Corey (1964). Moreover, Tani's (1982) retention model was combined with the Leibenzon model and used for analyzing the properties of one-dimensional unsaturated flow in a soil column (Tani, 1985). Sammori and Tsuboyama (1990) adopted the combined waterretention-hydraulic-conductivity model developed by van Genuchten (1980) to analyze slope stability taking infiltration into consideration.

Despite their usefulness, these combined models use empirical curve-fitting equations for the soil water retention curve. They are not derived based on soil pore radius distribution, nor do they emphasize the physical significance of their empirical parameters. Moreover, these combined models employ equations for the relative hydraulic conductivity. That is, the saturated hydraulic conductivity, which is closely related to the soil pore radius distribution, is regarded as one of the independent parameters in these combined models. Hence, these models cannot be effectively used for analyzing the effect of pore radius distribution of forest soils on the water movement phenomena.

Recently, Kosugi (1996) developed a com- bined water-retention-hydraulic-conductivity model by applying lognormal distribution laws to the soil pore radius distribution function. A model for the saturated hydraulic conductivity was also derived based on the lognormal distribution theory (Kosugi, 1997b). In the application of these models, soil hydraulic properties are characterized by two parameters, both of which are related directly to the statistics of the soil pore radius distribution. In this study, these models are adopted for physical analyses of soil water flow in order to evaluate the effect of the pore radius distribution of forest soils on vertical water movement phenomena in soil profile.

\section{THEORY}

\section{One-Dimensional Vertical Flow Equa- tion for Soil Water}

According to the Darcy-Backingham equation, vertical water flux $q$ in unsaturated soil is expressed as follows:

$$
q=-K(\psi)(\partial \psi / \partial z+1)
$$

where $K(\psi)$ is the hydraulic conductivity at a certain capillary pressure $\psi$ and $z$ is the vertical distance taken positive upward. The continuity equation for water is

$$
\partial \theta / \partial t=-\partial q / \partial z
$$

where $\theta$ is the volumetric soil water content and $t$ is time. Substituting Eq. (1) into Eq. (2) yields the one-dimensional, vertical flow equation for soil water (the Richards' equation):

$$
C(\psi) \frac{\partial \psi}{\partial t}=\frac{\partial}{\partial z}\left[K(\psi) \frac{\partial \psi}{\partial z}\right]+\frac{\partial}{\partial z} K(\psi)
$$

where $C(\psi)=d \theta / d \psi$ is the specific water capacity defined as the slope of the soil water retention curve $(\theta-\psi$ curve). Solving Eq. (3) requires the models for soil water retention and hydraulic conductivity.

\section{Model for Soil Hydraulic Properties}

Kosugi (1996) proposed the following model for the soil pore radius distribution function $g$ ( $r$ ) (in which $r$ is the pore radius), and the corresponding models for the effective saturation $S_{e}$ and the relative hydraulic conductivity $K_{r}$ : 


$$
\begin{aligned}
& g(r)=\frac{\theta_{s}-\theta_{r}}{\sqrt{2 \pi} \sigma r} \exp \left\{-\frac{\left[\ln \left(r / r_{m}\right)\right]^{2}}{2 \sigma^{2}}\right\} \\
& S_{e}=\left(\theta-\theta_{r}\right) /\left(\theta_{s}-\theta_{r}\right)=Q\left(\ln \left(\psi / \psi_{m}\right) / \sigma\right) \\
& K_{r}=K / K_{s}=S_{e} e^{1 / 2}\left[Q\left(\ln \left(\psi / \psi_{m}\right) / \sigma+\sigma\right)\right]^{2}
\end{aligned}
$$

where $K_{s}$ is the saturated hydraulic conductivity, and $\theta_{s}$ and $\theta_{r}$ are the saturated and residual water contents, respectively. $\theta_{r}$ is defined as the water content when $\psi$ is infinitely small, and the soil water conductivity is assumed to be zero. $Q$ in Eqs. (5) and (6) denotes the complementary normal distribution function defined as

$$
Q(x)=\int_{x}^{\infty} \frac{1}{\sqrt{2 \pi}} \exp \left(-\frac{x^{2}}{2}\right) d x
$$

Eq. (4) represents a lognormal distribution since the distribution of $\ln (r)$ conforms to $N$ (ln $\left.\left(r_{m}\right), \sigma^{2}\right)$. Parameter $r_{m}$ is equal to the median and the geometric mean of $g(r)$. Parameter $\sigma$ $(\sigma>0)$ is related to the width of $g(r)$ since it is the standard deviation of the distribution of $\ln$ $(r)$. The value of $\sigma$ is small for a soil which has a narrow pore radius distribution, and is large for a soil with a wide pore radius distribution. Equation (5) was derived from Eq. (4) on the basis of the direct correspondence of $r$ and $\psi$ expressed by the following capillary pressure function:

$$
\psi=-2 \gamma \cos \beta / \rho_{w} g r=A / r
$$

where $\gamma$ is the surface tension between the water and air, $\beta$ is the contact angle, $\rho_{w}$ is the density of water, and $g$ is the acceleration of gravity. The constant value of $-2 \gamma \cos \beta / \rho_{w} g=$ $A=-0.149 \mathrm{~cm}^{2}$ (Brutsaert, 1966) is used in this study. Parameter $\psi_{m}$ of Eq. (5) is related to the median $\left(r_{m}\right)$ of $g(r)$ by Eq. (8) (that is, $\psi_{m}$ $=A\left(r_{m}\right)$, and is equal to the capillary pressure when $S_{e}$ is equal to 0.5. Parameter $\sigma$ describes the slope of the water retention curve: the curve becomes steeper near the inflection point as $\sigma$ becomes smaller. Equation (6) was developed by substituting Eq. (5) into Mualem's (1976a) model to derive the $K_{t}-\psi$ relationship from soil water retention characteristics.

The following functional relationship between $K_{s}$ and the parameters of Eqs. (5) and (6) was derived based on Mualem's (1976a) model
(Kosugi, 1997b):

$$
K_{s}=B \exp \left(\sigma^{2}\right) / \psi_{m}^{2}
$$

The parameter $B$ is related to the effective porosity and the soil pore tortuosity. The value of $B$ was suggested to be $10^{0.4} \mathrm{~cm}^{3} / \mathrm{s}$ by Kosugi (1997b) as an average for some 257 forest soils. Substituting Eqs. (5) and (9) into Eq. (6) yields

$$
\begin{gathered}
K(\psi)=10^{0.4} \frac{\exp \left(\sigma^{2}\right)}{\psi_{m}^{2}}\left[Q\left(\frac{1}{\sigma} \ln \left(\frac{\psi}{\psi_{m}}\right)\right\}\right)^{1 / 2} \\
{\left[Q\left(\frac{1}{\sigma} \ln \left(\frac{\psi}{\psi_{m}}\right)+\sigma\right)\right]^{2}}
\end{gathered}
$$

The combination of the water retention model expressed as Eq. (5) and the hydraulic conductivity model expressed as Eq. (10) is referred to as the lognormal distribution model in this study. Applying this model, soil hydraulic properties are characterized by two parameters $\psi_{m}$ and $\sigma$; both of which are related directly to the statistics of the soil pore radius distribution. It should be noted that hysteretic phenomena found in soil hydraulic properties are assumed to be negligible in this study.

\section{APPLICATION OF THE LOGNOR- MAL DISTRIBUTION MODEL TO OBSERVED DATA SETS}

In Fig. 1, the observed $\theta-\psi$ and $K-\psi$ curves for two undisturbed forest soils are com.

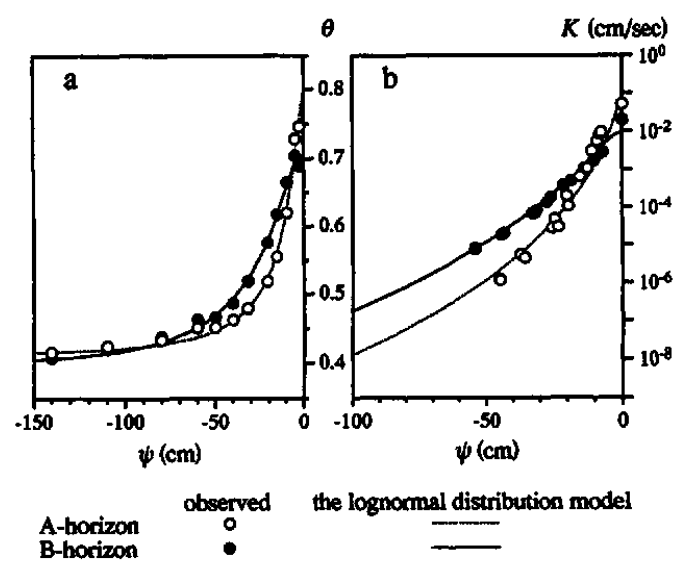

Fig. 1 (a)Observed and fitted $\theta-\psi$ curves, and (b)observed and predicted $K-\psi$ curves for undisturbed forest soils 
pared with the fitted $\theta-\psi$ and the predicted $K$ $-\psi$ curves obtained by the lognormal distribution model. One sample was taken from A-horizon (5 10cm deep from the soil surface), and the other sample was taken from B-horizon (30 $40 \mathrm{~cm}$ deep from the surface). Parameters $\theta_{s}, \theta_{r}$, $\psi_{m}$, and $\sigma$ in Eq. (5) were optimized to reproduce the observed $\theta-\psi$ curves by using a nonlinear least squares optimization procedure, then the $K-\psi$ curves were predicted by substituting the estimated $\psi_{m}$ and $\sigma$ into Eq. (10). The figure clearly shows that the lognormal dis. tribution model produces acceptable matches with the observed $\theta-\psi$ curves and adequate predictions of the $K-\psi$ curves. Table 1 summarizes the optimized values of $\theta_{s}, \theta_{r}, \psi_{m}$, and $\sigma$, and the observed and predicted $K_{s}$ values. The predicted $K_{s}$ values are about the same as the observed $K_{s}$ values.

Fig. 2 represents the relationship between $\psi_{m}$ and $\sigma$ estimated for the retention data sets of the undisturbed forest soils taken from Mashimo (1960), and the disturbed loamy and sandy soils taken from Mualem (1976b) and Nakajima (1995) (the same plots are shown in Fig. 3 of Kosugi (1997a)). The figure shows that $\sigma$ (that is, the width of $g(r)$ ) of the disturbed loamy soils is greater than that of the disturbed sandy soils, and $\psi_{m}$, which has a positive correlation with the median $\left(r_{m}\right)$ of $g(r)$, of the loamy soils is smaller than that of the sandy soils. Many of the undisturbed forest soils have greater median of $g(r)$ than the disturbed loamy soils and larger $g(r)$ width than the disturbed sandy soils. Textures of the forest soils shown in this figure range from heavy clay through sandy loam (Mashimo, 1960). Since the disturbed loamy soils have small $\psi_{m}$ values, it is reasonable to assume that the disturbed samples of these forest soils have smaller $\psi_{m}$ values than the original undisturbed samples. In Fig. 2, $\psi_{m}$ values for the massive forest soils, which can be regarded as undeveloped field soils, are smaller than those for the crumb and granular-structure forest soils. Many crumbstructure forest soils have greater $\psi_{m}$ values

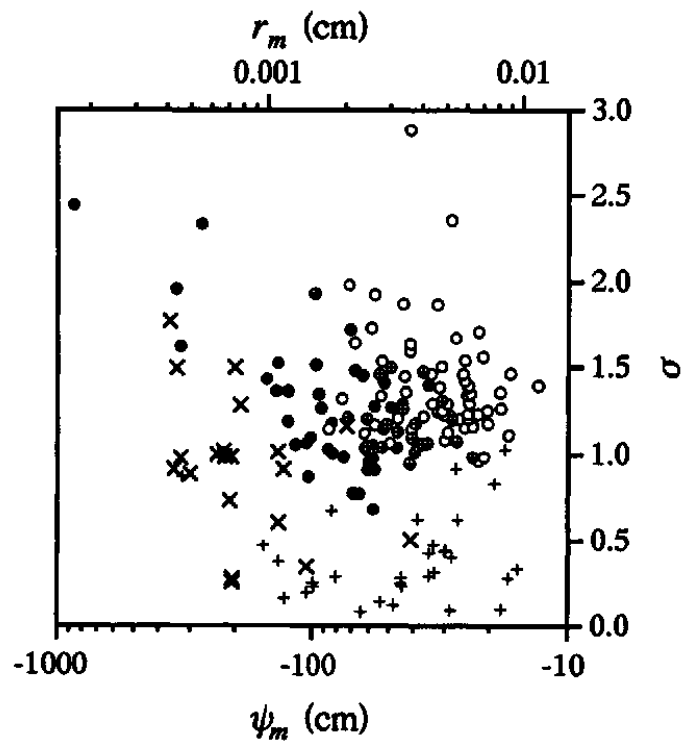

Undisturbed forest soils Disturbed soils

$\begin{array}{ll}\text { - crumb } & \times \text { loam } \\ \text { - granular } & + \text { sand }\end{array}$

Fig. 2 Relationship between $\psi_{m}$ and $\sigma$ estimated for the undisturbed forest soils (circles), and for the disturbed loamy and sandy soils (crosses and pluses). Each plot symbol represents the soil structure for the forest soils. The median $r_{m}$ of the pore radius distribution is related to $\psi_{m}$ by Eq. (8).

Table 1 Fitted Values for Parameters of the Lognormal Distribution Model for the Retention Curves Plotted in Fig. 1a, and Observed and Predicted Values of Saturated Hydraulic Conductivity

\begin{tabular}{lcccccc}
\hline Horizon & $\theta_{s}$ & $\theta_{r}$ & $\psi_{m}, \mathrm{~cm}$ & $\sigma$ & $\begin{array}{l}K_{s}, \mathrm{~cm} / \mathrm{sec} \\
\text { (predicted) }\end{array}$ & $\begin{array}{l}K_{s}, \mathrm{~cm} / \mathrm{sec} \\
\text { (observed) }\end{array}$ \\
\hline $\mathrm{A}$ & 0.788 & 0.412 & -11.6 & 1.105 & $6.37 \times 10^{-2}$ & $5.12 \times 10^{-2}$ \\
$\mathrm{~B}$ & 0.703 & 0.396 & -25.9 & 0.9252 & $8.80 \times 10^{-3}$ & $1.97 \times 10^{-2}$ \\
\hline
\end{tabular}


than the granular-structure forest soils. As a result, the process of the change of the soil pore radius distribution due to the forest ecosystem (forest plants and animals) can be regarded as a process increasing the median of the distribution.

\section{ANALYSIS OF VERTICAL WATER MOVEMENT IN SOIL PROFILE}

\section{Hydrographs under Natural Rainfall}

The vertical water movement in soil profile was simulated by using observed rainfall data as inputs for the water flux at the soil surface. The rainfall data set was observed at Toinotani watershed of the Kyoto University Forest in Ashu in September 1992. Equation (3) was solved using a finite difference scheme with 11 equally spaced nodes. The initial condition was hydraulic equilibrium under a zero-flux condition, that is

$$
\psi=-z \quad(0 \leq z \leq L)
$$

where $L$ is the vertical soil length. A constant water table condition $(\psi=0)$ at the bottom of a soil profile $(z=0)$ was imposed to compute the water discharge $q_{\text {out }}$. Value of $\sigma$ was either 0.5 or 1.5 , and $\psi_{m}$ were from -25 to $-200 \mathrm{~cm}$. The constant value of 0.3 was used as the effective porosity $\left(\theta_{s}-\theta_{r}\right)$. Cumulative errors in the mass balance at the end of calculations were negligible.

Fig. 3 shows the hydrographs computed with the $L$ value of $100 \mathrm{~cm}$. The peak of the flood hydrograph decreases and the slope of the reces. sion hydrograph becomes gradual as $\psi_{m}$ increases in both cases of $\sigma=0.5$ and $\sigma=1.5$. The recession hydrograph with the parameter set $\left(\psi_{m}, \sigma\right)$ of $(-25,0.5)$ has greater $q_{\text {out }}$ and more gradual decreases in $q_{\text {out }}$ than that with the parameter set of $(-25,1.5)$. The recession hydrograph with the parameter set of $(-100$, $0.5)$ has smaller $q_{\text {out }}$ and steeper decreases in $q_{\text {out }}$ than any recession hydrograph with $\sigma$ value of 1.5. That is, the effect of $\psi_{m}$ on the recession hydrograph is greater in the case of $\sigma=0.5$ than in the case of $\sigma=1.5$.
The computed $q_{\text {out }}-t$ relationships with the $L$ value of $50 \mathrm{~cm}$, are shown in Fig. 4. The recession hydrograph becomes more gradual as $\psi_{m}$ increases in both cases of $\sigma=0.5$ and $\sigma=1.5$. The recession hydrograph with the parameter set of $(-25,0.5)$ has the smallest decreases in $q_{\text {out }}$. The recession hydrograph with the parameter set of $(-50,0.5)$ is about the same as the

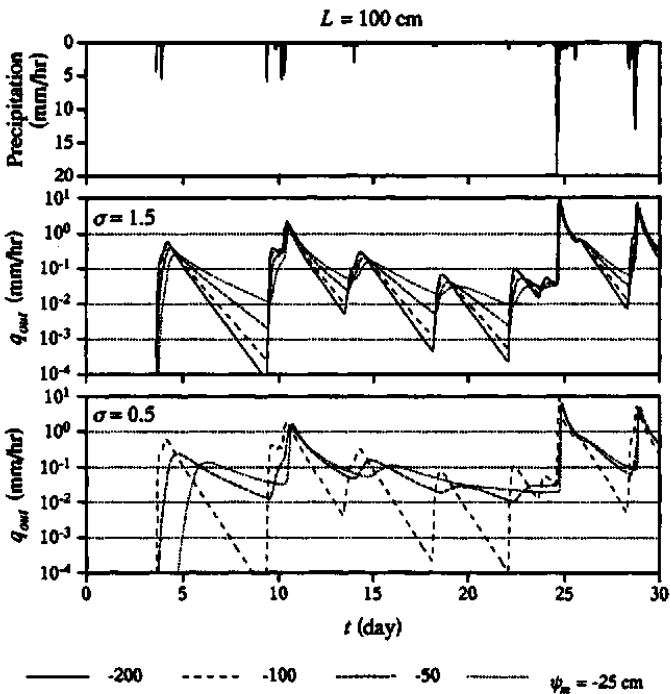

Fig. 3 Simulated hydrographs from the soil profile with the length of $100 \mathrm{~cm}$

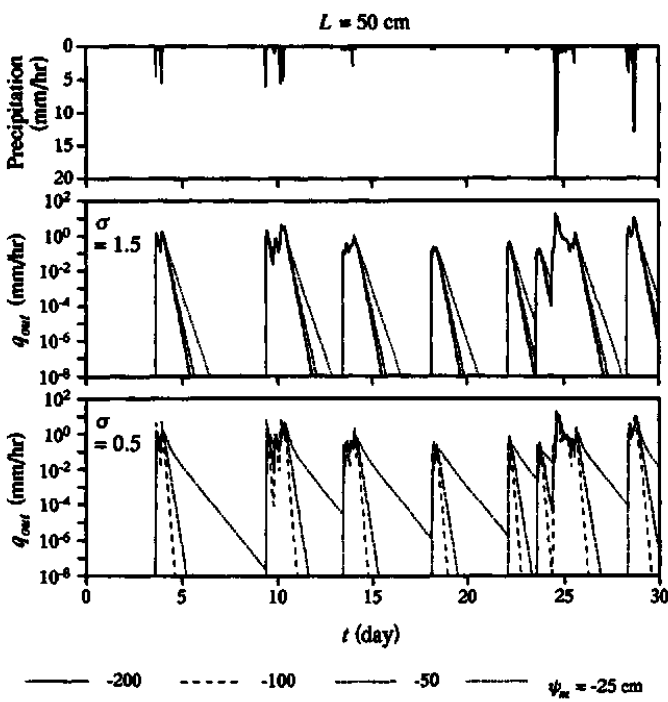

Fig. 4 Simulated hydrographs from the soil profile with the length of $50 \mathrm{~cm}$ 
recession hydrographs with the parameter sets of $(-100,1.5)$ and $(-200,1.5)$.

Fig. 5 shows the computed $q_{\text {out }}-t$ relationships when $L$ is $150 \mathrm{~cm}$. The recession hydrograph with the parameter set of $(-50$. 0.5 ) is more gradual than that with the parameter set of $(-50,1.5)$, and the recession hydrograph with the parameter set of $(-200$, $0.5)$ is steeper than that with the parameter set of $(-200,1.5)$. The recession hydrograph with the parameter set of $(-100,0.5)$ is about the same as that with the parameter set of $(-100$. 1.5). To be precise, the former has slightly greater $q_{\text {out }}$ values than the latter.

Fig. 3 through Fig. 5 clearly show that the recession hydrographs plotted using a semi-logarithmic scale are almost straight. The increase in the vertical soil length $L$ makes the slope of the recession hydrograph gradual. Under the same $L$ and $\sigma$ condition, the recession hydrograph with greater $\psi_{m}$ value has greater $q_{\text {out }}$ and more gradual decreases in $q_{\text {out }}$. With a large $\psi_{m}$ value, the recession hydrograph is more gradual in the case of $\sigma=0.5$ than in the case of $\sigma=1.5$. When $\psi_{m}$ is small, the recession hydrograph is steeper in the case of $\sigma=0.5$ than in the case of $\sigma=1.5$. This critical $\psi_{m}$ value in-

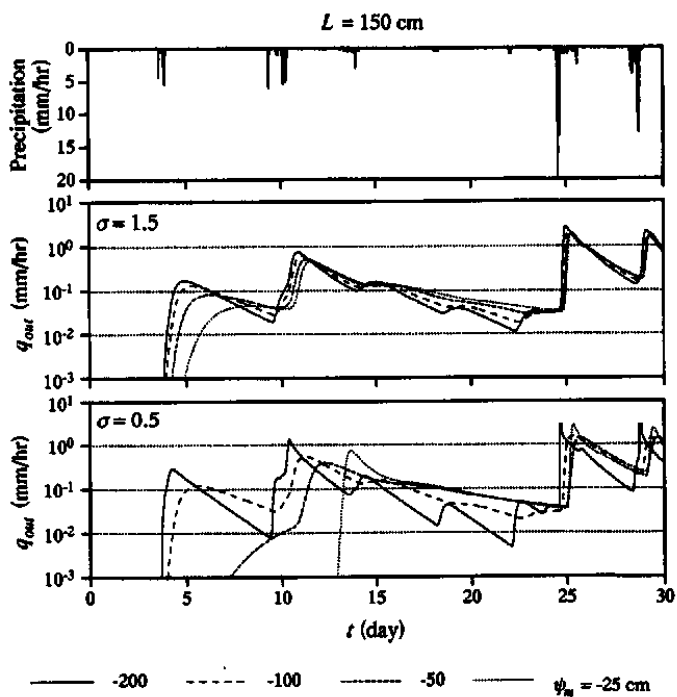

Fig. 5 Simulated hydrographs from the soil profile with the length of $150 \mathrm{~cm}$ creases as $L$ decreases.

According to Eq. (9), the saturated hydraulic conductivity $K_{s}$ becomes larger as the median of the soil pore radius distribution becomes greater (that is, $\psi_{m}$ becomes greater), and the width of the pore radius distribution $(\sigma)$ becomes greater. However, Fig. 3 through Fig. 5 indicate that the increase in $K_{s}$ does not necessarily make the recession hydrograph steep. In the following subsections, the slope of the recession hydrograph is analyzed in connection with the unsaturated soil hydraulic properties and the soil pore radius distribution.

\section{Analytical Solution of the One-Dimen- sional Vertical Flow Equation}

When the vertical soil length is not so large, the second term of the right-hand side of Eq. (3) is negligible in comparison with the first term for analyzing the recession hydrograph (Seguchi et al., 1982). By neglecting the second term of Eq. (3) and assuming that the soil water diffusivity $D(=K / C)$ is a constant $D_{a}$ (Gardner, 1962; Seguchi et al., 1982), Eq. (3) is transformed as follows:

$$
\frac{\partial \theta}{\partial t}=D_{a} \frac{\partial^{2} \theta}{\partial z^{2}}
$$

The constant $D_{a}$ is referred to as the mean diffusivity. Eq. (12) can be solved analytically under the following initial and boundary conditions (Swartzendruber, 1969):

$$
\begin{array}{ll}
\theta=\theta_{s} & (0 \leq z \leq L, t=0) \\
\theta=\theta_{s} & (z=0, t>0) \\
\partial \theta / \partial z=-b & (z=L, t>0)
\end{array}
$$

where $b$ is a positive constant. The analytical solution of Eq. (12) is

$$
\begin{aligned}
\theta= & \theta_{s}-b z-\frac{8 b L}{\pi^{2}} \sum_{i=1}^{\infty} \frac{(-1)^{i}}{(2 i-1)^{2}} \sin \left(\frac{2 i-1}{2} \frac{\pi}{L} z\right) \\
& \exp \left[-\left(\frac{2 i-1}{2}\right)^{2} \frac{\pi^{2} D_{a}}{L^{2}} t\right]
\end{aligned}
$$

The water discharge at the bottom of soil profile $q_{\text {out }}$ is expressed as

$$
q_{\text {out }}=\frac{\partial}{\partial t} \int_{0}^{L}\left(\theta_{s}-\theta\right) d z
$$

Neglecting all but the first term of the series of 
Eq. (14) and substituting into Eq. (15) yields

$$
q_{\text {out }}=\frac{4 b D_{a}}{\pi} \exp \left(-\frac{\pi^{2} D_{a}}{4 L^{2}} t\right)
$$

Eq. (16) indicates that $q_{\text {out }}$ is expressed as an exponential function with respect to $t$. This coincides with the result derived by the numerical solution of Eq. (3): the recession hydrographs are almost straight in Fig. 3 through Fig. 5. According to Eq. (16), the absolute value of the slope of the recession hydrograph plotted using a semi-logarithmic scale $(a)$ is expressed as follows:

$$
a=\frac{\pi^{2}}{4} \frac{D_{a}}{L^{2}}
$$

Value of $a$ increases as $L$ decreases. This also coincides with the result shown in Fig. 3 through Fig. 5: the decrease in $L$ makes the simulated recession hydrographs steep. As a result, Eq. (16) can be successfully used to analyze the vertical drainage process in soil profile.

\section{Relationship between the Slope of the Recession Hydrograph and the Soil Wa ter Diffusivity}

Eq. (17) indicates that $a$ is in proportion to the mean diffusivity $D_{a}$. On the other hand, the soil water diffusivity $D$ based on the lognormal distribution model can be derived from Eqs. (5) and (10) as a function of $\psi$.

$$
\begin{aligned}
D(\psi)= & \frac{10^{0.4} \sqrt{2 \pi} \sigma_{\exp }\left(\sigma^{2}\right)}{\left(\theta_{s}-\theta_{r}\right) \psi_{m}^{2}} \\
& \frac{(-\psi)\left[Q\left(\ln \left(\psi / \psi_{m}\right) / \sigma\right)\right]^{1 / 2}\left[Q\left(\ln \left(\psi / \psi_{m}\right) / \sigma+\sigma\right)\right]^{2}}{\exp \left\{-\left[\ln \left(\psi / \psi_{m}\right)\right]^{2} / 2 \sigma^{2}\right\}}
\end{aligned}
$$

Plots of Eq. (18) with 8 different parameter sets $\left(\psi_{m}, \sigma\right)$ are shown in Fig. 6. The parameter sets are the same as those used for computing the hydrographs shown in Fig. 3 through Fig. 5. The $D-\psi$ curves with the $\sigma$ value of 0.5 have greater decreases in $D$ as $\psi$ decreases than the $D-\psi$ curves with the $\sigma$ value of 1.5 . Under the same $\sigma$ value condition, $D$ at a certain $\psi$ value decreases as $\psi_{m}$ increases. The change of $D-\psi$ curve as $\psi_{m}$ changes is greater

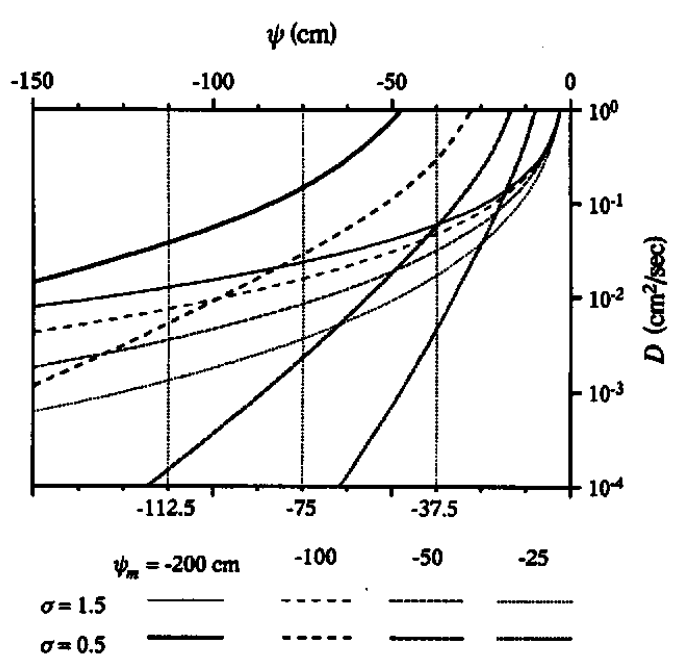

Fig. 6 Curves for $D-\psi$ based on the lognormal distribution model, showing plots of Eq. (18) with 8 different parameter sets $\left(\psi_{m}, \sigma\right)$

in the case of $\sigma=0.5$ than in the case of $\sigma=1.5$.

When the vertical soil length is $L, \psi$ value in the soil profile changes in the range of 0 to $-L$ during the vertical drainage process with the constant water table at the bottom of the soil profile. Here, it is assumed that the mean diffusivity $D_{a}$ has a positive correlation with $D$ at a certain $\psi$ value in the range of 0 to $-L$, which can be written as $D(-\eta L)$ using a constant $\eta(0<\eta<1)$. Then, the slope of recession hydrograph, which is related to $D_{a}$ by Eq. (17), is expected to have a correlation with the $D(-\eta L)$ value.

When $\eta$ is assumed to be $0.75,-\eta L$ is equal to $-75 \mathrm{~cm}$ for the soil profile with the length of $100 \mathrm{~cm}$. Fig. 6 shows that the values of $D(-75)$ for the parameter sets $\left(\psi_{m}, \sigma\right)$ of $(-25,0.5)$ and $(-50,0.5)$ are smaller than that for the parameter set of $(-25,1.5)$. Value of $D(-75)$ for the parameter set of $(-100,0.5)$ is greater than any $D(-75)$ value for the parameter set with $\sigma$ value of 1.5. The slopes of the recession hydrographs shown in Fig. 3 seem closely related to these $D(-75)$ values: the absolute value of the slope of the recession hydrograph decreases as $D(-75)$ decreases. 
With the assumption of $\eta=0.75,-\eta L$ value is equal to $-37.5 \mathrm{~cm}$ for the soil profile with the length of $50 \mathrm{~cm}$. Value of $D(-37.5)$ for the parameter set of $(-25,0.5)$ is smallest in Fig. 6, and $D(-37.5)$ for the parameter set of $(-100,0.5)$ is great. Value of $D(-37.5)$ for the parameter set of $(-50,0.5)$ is about the same as those for the parameter sets of $(-100,1.5)$ and $(-200,1.5)$. These $D(-37.5)$ values seem positively correlated with the absolute values of the slopes of the recession hydrographs shown in Fig. 4.

For the soil profile with the length of $150 \mathrm{~cm}$, $-\eta L$ value is $-112.5 \mathrm{~cm}$ when $\eta$ is assumed to be 0.75 . Value of $D(-112.5)$ for the parameter set of $(-50,0.5)$ is smaller than that for the parameter set of $(-50,1.5)$, and $D(-112.5)$ for the parameter set of $(-200,0.5)$ is greater than that for the parameter set of $(-200,1.5)$. Values of $D(-112.5)$ for the parameter sets of $(-100,0.5)$ and $(-100,1.5)$ are similar to each other. Precisely, the former is smaller than the latter. There seems a positive correlation between these $D(-112.5)$ values and the absolute values of the slopes of the recession hydrographs shown in Fig. 5.

Fig. 3 through Fig. 6 suggest that the $D$ ($\eta L)$ value is closely related to the mean diffusivity $D_{a}$ and the slope of the recession hydrograph when $\eta$ is 0.75 . In order to clarify that this result is applicable to soil profile with any given length and with varying hydraulic properties, all the aforementioned equations were made dimensionless by using the following dimensionless variables:

$$
\begin{array}{ll}
z_{*}=z / L & t_{*}=t K_{s} / L\left(\theta_{s}-\theta_{r}\right) \\
q_{*}=q / K_{s} & \psi_{*}=-\psi / \psi_{m}
\end{array}
$$

The resulting dimensionless form of Eq. (3) is

$$
C_{*} \frac{\partial \psi_{*}}{\partial t_{*}}=\frac{\partial}{\partial z_{*}}\left[K_{r}\left(\xi \frac{\partial \psi_{*}}{\partial z_{*}}\right)\right]+\frac{\partial}{\partial z_{*}} K_{r} \quad \text { (20) }
$$

where $C_{*}\left(=d S_{e} / d \psi_{*}\right)$ is the dimensionless soil water capacity and $\xi$ is the dimensionless parameter defined as

$$
\xi=-\psi_{m} / L
$$

Eq. (20) is transformed as follows by neglect- ing the second term of the right-hand side and assuming that the dimensionless soil water diffusivity $D_{*}\left(=K_{r} / C_{*}\right)$ is a constant $D_{a *}$ :

$$
\frac{\partial S_{e}}{\partial t_{*}}=\xi D_{a *} \frac{\partial^{2} S_{e}}{\partial z_{*}^{2}}
$$

The relationship between the dimensionless mean diffusivity $D_{a *}$ and $D_{a}$ is

$$
D_{a}=\frac{\left(-\psi_{m}\right) K_{s}}{\theta_{s}-\theta_{r}} D_{a *}=\frac{10^{0.4}}{L\left(\theta_{s}-\theta_{r}\right)} \frac{\exp \left(\sigma^{2}\right)}{\xi} D_{a *}
$$

Eq. (22) can be solved analytically under the following initial and boundary conditions by the same procedure used to solve Eq. (12):

$$
\begin{array}{lc}
S_{e}=1 & \left(0 \leq z_{*} \leq 1, t_{*}=0\right) \\
S_{e}=1 & \left(z_{*}=0, t_{*}>0\right) \\
\partial S_{e} / \partial z_{*}=-b_{*} / \xi & \left(z_{*}=1, t_{*}>0\right)
\end{array}
$$

where $b_{*}$ is a positive constant. The resulting relationship between the water discharge $q_{\text {out }}$ and $t_{*}$ is

$$
q_{\text {out* }}=\frac{4 b_{*} D_{a *}}{\pi} \exp \left(-\frac{\pi^{2} \xi D_{a *}}{4} t_{*}\right)
$$

Hence, the absolute value of the slope of the dimensionless recession hydrograph plotted using a semi-logarithmic scale $\left(a_{*}\right)$ is expressed as follows:

$$
a_{*}=\frac{\pi^{2}}{4} \xi D_{a *}
$$

On the other hand, the expression of the dimensionless soil water diffusivity $D_{*}$ is

$$
D_{*}\left(\psi_{*}\right)=\frac{\sqrt{2 \pi} \sigma\left(-\psi_{*}\right)\left[Q\left(\ln \left(-\psi_{*}\right) / \sigma\right)\right]^{1 / 2}\left[Q\left(\ln \left(-\psi_{*}\right) / \sigma+\sigma\right)\right]^{2}}{\exp \left\{-\left[\ln \left(-\psi_{*}\right)\right]^{2} / 2 \sigma^{2}\right\}}
$$

The relationship between $D_{*}$ and $D$ is

$$
\begin{aligned}
D(\psi) & =\frac{\left(-\psi_{m}\right) K_{s}}{\theta_{s}-\theta_{r}} D_{*}\left(\psi_{*}\right) \\
& =\frac{10^{0.4}}{L\left(\theta_{s}-\theta_{r}\right)} \frac{\exp \left(\sigma^{2}\right)}{\xi} D_{*}\left(\psi_{*}\right)
\end{aligned}
$$

In the dimensionless vertical drainage process, $\psi_{*}$ value in the soil profile changes in the range of 0 to $-1 / \xi$. According to the result suggested by Fig. 3 through Fig. 6, it is expected that $D_{*}(-\eta / \xi)$ is closely related to $D_{a *}$ when $\eta$ is equal to 0.75 . In Fig. 7 , the relationship between $D_{*}(-0.75 / \xi)$ and $D_{a *}$ obtained for 55 different parameter sets $(\xi, \sigma)$ is shown 


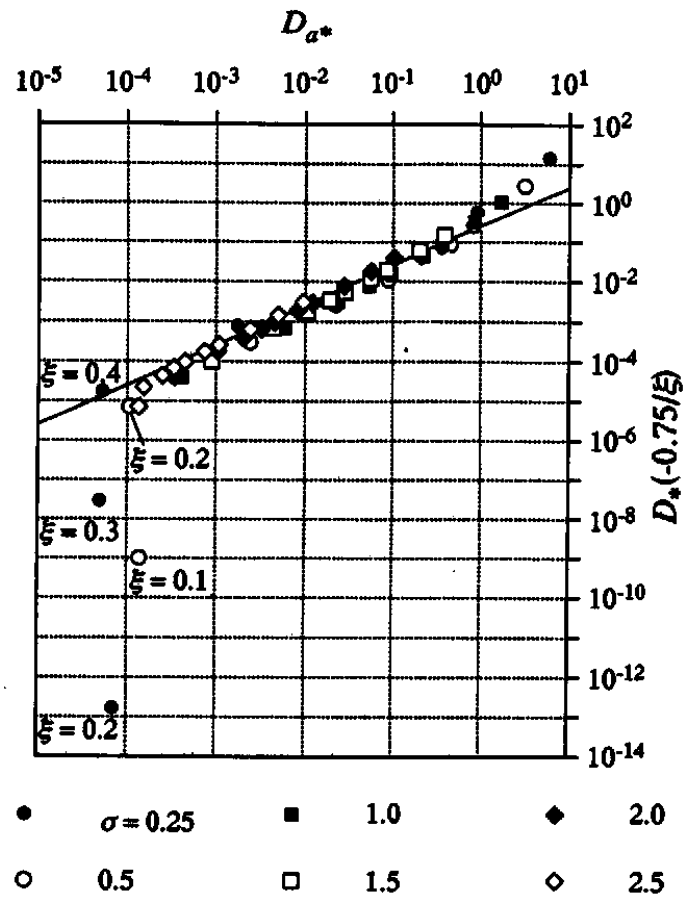

Fig. 7 Relationship between $D_{*}(-0.75 / \xi)$ and $D_{a *}$ obtained for 55 different parameter sets $(\xi, \sigma)$. Values of $\xi$ were from 0.2 to 1.5 for $\sigma$ value of 0.25 , from 0.1 to 2.0 for $\sigma$ value of 0.5 , from 0.1 to 4.0 for $\sigma$ values of 1.0 and 1.5 , and from 0.1 to 8.0 for $\sigma$ values of 2.0 and 2.5.

using a logarithmic scale. Values of $\sigma$ were $0.25,0.5,1.0,1.5,2.0$, and 2.5. Values of $\xi$ were 0.2 and higher when $\sigma=0.25$, and 0.1 and higher for other $\sigma$ values. Value of $D_{a *}$ for each parameter set was computed by Eq. (26) using the $a_{*}$ value obtained by the numerical solution of Eq. (20). The initial condition for the numerical solution was the water saturation with a constant flux of $q_{*}=-1$, and the zeroflux condition $\left(q_{*}=0\right)$ at the soil surface and the constant water table condition $\left(\psi_{*}=0\right)$ at the bottom of soil profile were imposed to compute the $a_{*}$ value. Fig. 7 shows that most of the points can be plotted along a straight line with a unit gradient. The relationship between $D$ * $(-0.75 / \xi)$ and $D_{a *}$ expressed by the fitted line is

$$
D_{a *}=4 D .(-0.75 / \xi)
$$

Since $D_{a *}$ and $D_{*}(-0.75 / \xi)$ are transformed into $D_{a}$ and $D(-0.75 L)$ by Eqs. (23) and (28), respectively, Eq. (29) indicates that $D_{a}$ for the soil profile with the vertical length of $L$ has a positive correlation with $D(-0.75 L)$. As a result, $D(-0.75 L)$ can be successfully used as an index of the mean diffusivity $D_{a}$, which describes the slope of the recession hydrograph. In Fig. 7, the points for the parameter sets $(\xi$, $\sigma)$ of $(0.2,0.25),(0.3,0.25)$, and $(0.1,0.5)$ are not plotted on the straight line. That is, Eq. (29) is not applicable in the range of $\psi_{m}>-$ $60 \mathrm{~cm}$ with $\sigma=0.25$ and in the range of $\psi_{m}>-$ $30 \mathrm{~cm}$ with $\sigma=0.5$ when $L$ is $150 \mathrm{~cm}$. One can see that the parameter set $\left(\psi_{m}, \sigma\right)$ of $(-25 \mathrm{~cm}, 0.5)$ used in Fig. 5 is in these ranges. When $L$ is $100 \mathrm{~cm}, \mathrm{Eq} .(29)$ is not applicable in the range of $\psi_{m}>-40 \mathrm{~cm}$ with $\sigma=0.25$ and in the range of $\psi_{m}$ $>-20 \mathrm{~cm}$ with $\sigma=0.5$; however, only a few soils exist in these ranges (Fig. 2).

\section{Effects of the Soil Pore Radius Distribu tion on the Recession Hydrograph}

Figs. $8 \mathrm{a}, 8 \mathrm{~b}$, and $8 \mathrm{c}$ are coordinate systems with $\psi_{m}$ on the abscissa and $\sigma$ on the ordinate showing the constant $\log [D(-0.75 L)]$ lines ( $D$ in $\mathrm{cm}^{2} / \mathrm{sec}$ ) with the $L$ values of 150,100 , and $50 \mathrm{~cm}$, respectively. As shown in the previous subsection, there is a positive correlation between $D(-0.75 L)$ and the absolute value of the slope of the recession hydrograph. Consequently, Figs. 8a through $8 \mathrm{c}$ can be used to evaluate the effect of parameters $\psi_{m}$ and $\sigma$ on the recession hydrograph. $\psi_{m}$ has a positive correlation with the median of $g(r)$ by Eq. (8), and $\sigma$ represents the width of $g(r)$. Fig. 8 clearly shows that the recession hydrograph becomes gradual as the median of $g(r)$ increases. For the soil with a relatively large median of $g$ $(r)$, the recession hydrograph becomes steep as the width of $g(r)$ increases. When the median of $g(r)$ is relatively small, the hydrograph has more gradual decreases in recession flow as the width of $g(r)$ increases. This critical value of the median of $g(r)$ increases as the length of 
soil profile decreases.

As shown in Fig. 2, $\psi_{m}$ values for the undisturbed forest soils are greater than those for the disturbed loamy soils. Fig. 8 indicates that hydrographs of the forest soils have more gradual decreases in recession flow than those of the loamy soils. Comparing Fig. $8 \mathrm{~b}$ with Fig. 2, it can be said that about 70 percent of the disturbed sandy soils yield greater amount of recession flow than the forest soils with the $L$ value of $100 \mathrm{~cm}$. When $L$ is $50 \mathrm{~cm}$, about half of the sandy soils yield smaller amount of recession flow than the forest soils (Fig. 8c). Many crumb-structure forest soils have greater $\psi_{m}$ values than the granular-structure forest soils, and $\psi_{m}$ values for massive forest soils are smaller than those for the crumb and granularstructure soils (Fig. 2). That is, hydrographs from the crumb-structure soils generally have more gradual decreases in recession flow than those from the granular-structure soils. The recession hydrographs from the massive soils are steeper than those from the crumb and granular -structure soils.

From Fig. 2, the process of the change of the soil pore radius distribution due to the forest ecosystem can be regarded as a process increasing the median of the distribution. Eq. (9) indicates that $K_{s}$ becomes larger as $\psi_{m}$ becomes greater. The large $K_{s}$ value decreases surface flow and increases the amount of water which infiltrates into the soil profile. Moreover, it was shown in this study that the soil profile with a greater $\psi_{m}$ value yields greater amount of recession flow in the vertical drainage process. Consequently, it can be said that the welldeveloped forest soil is effective as the surface soil to increase baseflow from hillslope.

\section{SUMMARY AND CONCLUSIONS}

In order to clarify the effect of soil pore radius distribution $g(r)$ on the phenomena of water movement in soil profile, one-dimensional, vertical flow equation for soil water (the Richards' equation) was solved numerically by using the model for soil hydraulic properties which was derived by applying lognormal distribution laws to $g(r)$. Results showed that the recession hydrograph from a soil profile becomes gradual as the median of $g(r)$ increases. For the soil with a relatively large median of $g$ $(r)$, the recession hydrograph becomes steep as the width of $g(r)$ increases. When the median of $g(r)$ of the soil is relatively small, the hydrograph has more gradual decreases in recession flow as the width of $g(r)$ increases. This critical value of the median of $g(r)$ increases as the length of soil profile decreases.

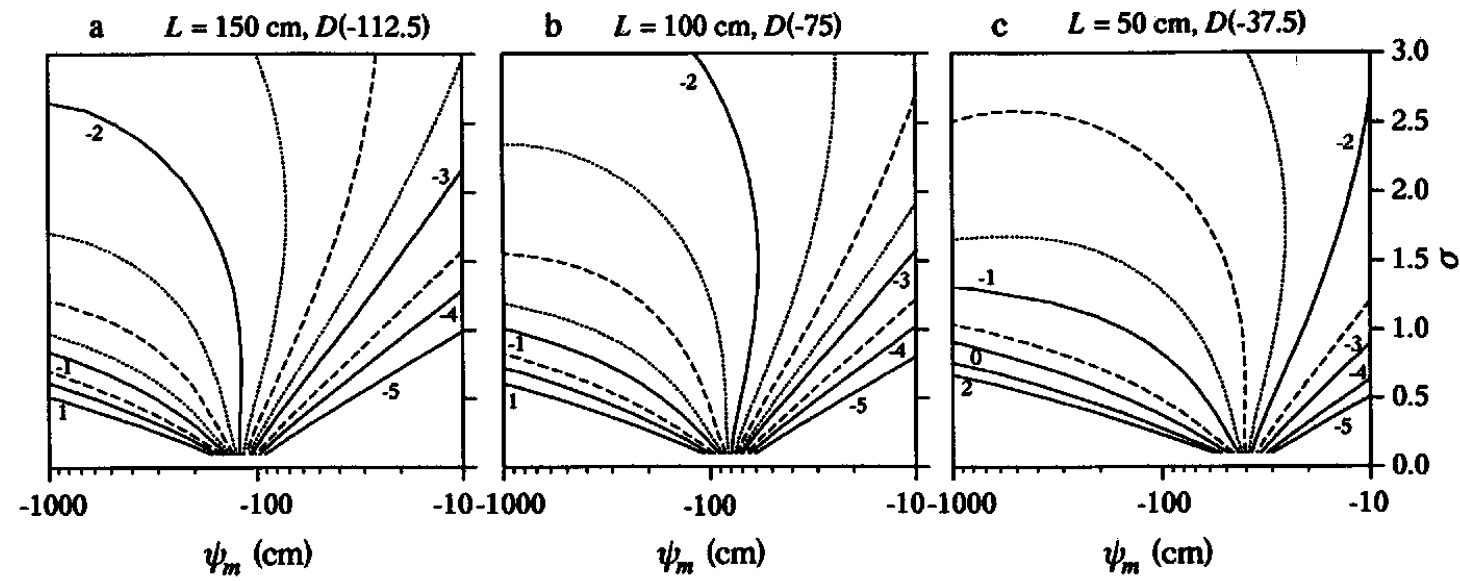

Fig. 8 Coordinate systems with $\psi_{m}$ on the abscissa and $\sigma$ on the ordinate, showing the constant $\log [D(-0.75 L)]$ lines $\left(D\right.$ in $\left.\mathrm{cm}^{2} / \mathrm{sec}\right)$ with the $L$ values of (a)150, (b)100, and (c)50cm 
Based on the analytical solution of the one-dimensional vertical flow equation, it was shown that, in the drainage process in the soil profile of length $L$, the soil water diffusivity at the capillary pressure value of $-0.75 \times L$ (that is, $D(-0.75 L)$ ) can be used as an index of the slope of the recession hydrograph. By comparing $D(-0.75 L)$ values of various soils, it was shown that the undisturbed forest soils yield greater amount of recession flow in the vertical drainage process than the disturbed loamy soils. About 70 percent of the disturbed sandy soils yield greater amount of recession flow than the forest soils with the $L$ value of $100 \mathrm{~cm}$. When $L$ is $50 \mathrm{~cm}$, hydrographs of about half of the sandy soils have greater decreases in recession flow than those of the forest soils. Hydrographs from the crumb-structure forest soils have more gradual decreases in recession flow than those from the granular-structure forest soils. The recession hydrographs from the massive forest soils are steeper than the those from the crumb and granular-structure soils.

ACKNOWLEDGEMENTS: I express my gratitude to Prof. S. Kobashi, Prof. T. Mizuyama, Dr. M. Fujita, Dr. N. Ohte (all of Kyoto University), and Dr. M. Suzuki (University of Tokyo) for valuable comments and criticisms of the manuscript. This research was partly supported by a grant from the Fund of Monbusyo for Scientific Research (NO. 07760151).

\section{REFERENCES}

Brooks, R.H. and A.T. Corey (1964): Hydraulic Properties of Porous Media, Hydrol. Pap. 3, 27 pp., Civil Eng. Dept., Colo. State Univ., Fort Collins.

Brutsaert, W. (1966): Probability laws for pore -size distributions, Soil Sci., 101, pp. 85-92.

Gardner, W.R. (1962): Approximate solution of a non-steady-state drainage problem, Soil Sci. Soc. Am. Proc., 26, pp. 129-132.

Klute, A. and D.F. Heermann (1974): Soil wa- ter profile development under a periodic boundary condition, Soil Sci., 117, pp. 265271.

Kosugi, K. (1996): Lognormal distribution model for unsaturated soil hydraulic properties, Water Resour. Res., 32, pp. 2697-2703.

Kosugi, K. (1997a): A new model to analyze water retention characteristics of forest soils based on soil pore radius distribution, J. For. Res., 2, pp. 1-8.

Kosugi, K. (1997b): New diagrams to evaluate soil pore radius distribution and saturated hydraulic conductivity of forest soil, J. For. Res. (in press).

Kubota, J., Y. Fukushima and M. Suzuki (1987): Observation and modeling of the runoff process on a hillslope, J. Jpn. For. Soc., 69, pp. 258-269 (in Japanese with English Sum. mary).

Leibenzon, L.S. (1947): Flow of Natural Liquids and Gases in Porous Medium (in Russian), Gostekhizdat, Moscow.

Mashimo, Y. (1960): Studies on the physical properties of forest soil and their relation to the growth of sugi (Cryptomeria japonica) and hinoki (Chamaecyparis obtusa), For. Soils Jpn., 11, pp. 1-182 (in Japanese with English Summary).

Mualem, Y. (1976a): A new model for predicting the hydraulic conductivity of unsaturated porous media, Water Resour. Res., 12, pp. 513-522.

Mualem, Y. (1976b): A Catalogue of the Hydraulic Properties of Unsaturated Soils, 100 pp., Technion-Israel Inst. of Technol., Haifa, Israel.

Nakajima, K. (1995): Estimation of Evapotranspiration on Non-Irrigated Lands in the Arid District of Central Asia, 45 pp., A graduation thesis, Kyoto Univ. (in Japanese)*

Ohte, N. (1992): Studies on Pore Structure and Hydraulic Properties of Forest Soils, 121 pp., A doctor thesis, Kyoto Univ. (in Japanese) *. 
Sammori, T. and Y. Tsuboyama (1990): Study on method of slope stability considering infiltration phenomenon, J. Jpn. Soc. Erosion Control Eng., 43 (4), pp. 14-21 (in Japanese with English Summary).

Seguchi, M., K. Tanaka and S. Shikasho (1982): Baseflow recession curve of small mountain river and its physical significances, Trans. JSIDRE, 97, pp. 1-8 (in Japanese with English summary) .

Swartzendruber, D. (1969): The flow of water in unsaturated soils, in Flow through Porous Media, edited by R.J.M. De Wiest, pp. 215292, Academic Press, New York.

Tani, M. (1982): The properties of a watertable rise produced by a one-dimensional, vertical, unsaturated flow, J. Jpn. For.
Soc., 64, pp. 409-418 (in Japanese with English summary).

Tani, M. (1985): Analysis of one-dimensional, vertical, unsaturated flow in consideration of runoff properties of a mountainous watershed, J. Jpn. For. Soc., 67, pp. 449460 (in Japanese with English summary).

Tsukamoto, Y. (1992): Forest Hydrology, pp. 37-41, Buneido, Tokyo (in Japanese)* van Genuchten, M.T. (1980): A closed-form equation for predicting the hydraulic conductivity of unsaturated soils, Soil Sci. Soc. Am. J., 44, pp. 892-898.

*The title is tentative translation from the original Japanese title by the author of this thesis.

(Received: Sep. 2, 1996, Accepted: Feb. 19, 1997) 